\title{
La influencia de la formación, la experiencia y la motivación para emprender en la supervivencia de las empresas de nueva creación
}

\author{
VIRGINIA SIMÓN MOYA, MSc., ${ }^{1,2}$ \\ Universidad de Valencia, España. \\ virsimo@alumni.uv.es \\ LORENZO REVUELTO TABOADA, Ph.D. \\ Profesor, Universidad de Valencia, España. \\ Lorenzo.revuelto@uv.es
}

\begin{abstract}
AIDA FLORENCIA MEDINA LORZA, Ph.D. (c)
Profesor tiempo completo, Universidad Icesi, Colombia.

afmedina@icesi.edu.co
\end{abstract}

\section{RESUMEN}

Este artículo analiza las diferencias en el nivel de supervivencia entre el emprendimiento social y el emprendimiento de negocios, así como el efecto de la formación, experiencia y motivación para emprender sobre la supervivencia. Dada la naturaleza de las variables dependientes, se optó por utilizar la prueba de Pearson, la prueba de Mann-Whitney para dos muestras independientes y el modelo logit sobre una muestra de 2.175 empresas. Los resultados no muestran diferencias significativas en la probabilidad de sobrevivir entre los dos tipos de emprendimiento, pero sí parecen mostrar la existencia de diferencias significativas en la influencia de las variables independientes analizadas sobre la supervivencia.

Palabras clave. Emprendimiento social; emprendimiento de negocios; supervivencia.

Recibido: 30-jun-11, corregido: 27-abr-12 y aceptado: 26-jun-12

Clasificación JEL: M130

$\infty$

1 Este documento fue seleccionado en la convocatoria para enviar artículos, Call for Papers, realizada en el marco del “II Simposio Iberoamericano de Estudios Gerenciales: Una mirada interdisciplinar a la innovación”, organizado por la revista académica Estudios Gerenciales bajo la dirección de la Facultad de Ciencias Administrativas y Económicas de la Universidad Icesi; el evento tuvo lugar los días 12, 13 y 14 de octubre de 2011, en la ciudad de Cali (Colombia). Este documento fue presentado en las sesiones simultáneas del área de "Innovación en emprendimiento".

2 Autor para correspondencia. Dirigir a: Departamento de Dirección de Empresas, Universidad de Valencia, Av. Los Naranjos s/N, 46022, Valencia, España. 


\section{The influence of education, experience, and entrepreneurial motivation on the survival of start-up companies}

This article analyzes the difference on the rates of survival between social entrepreneurship and business entrepreneurship and the effect of education, experience, and entrepreneurial motivation on survival. Given the nature of the dependent variables, the Pearson's test, the Mann-Whitney's test for two independent samples, and the logit model were applied to a sample consisting of 2,175 companies. The results didn't show significant differences in the likelihood of survival between these two kinds of entrepreneurship, but they seem to provide evidence of significant differences in the influence of independent variables on survival.

Keywords. Social entrepreneurship; business entrepreneurship; survival.

\section{es}

\section{A influência da formação, experiência e motivação para se engajar na sobrevivência de novas empresas}

Este artigo discute as diferenças na taxa de sobrevivência entre empreendedorismo social e empreendedorismo de negócios, assim como o efeito do treinamento, da experiência e da motivação para assumir a sobrevivência. Dada a natureza das variáveis dependentes, optou-se por utilizar o teste de Pearson, o teste de Mann-Whitney para as duas amostras independentes e do modelo logit em uma amostra de 2.175 empresas. Os resultados não mostram diferença significativa na probabilidade de sobrevivência entre os dois tipos de empreendedorismo, mas parecem mostrar a existência de diferenças significativas na influência das variáveis independentes analisadas na sobrevivência.

Palavras-chave. Empreendedorismo social; empreendedorismo de negócios; sobrevivência. 


\section{Introducción}

El fenómeno del emprendimiento no se restringe en la actualidad al emprendimiento en su concepción más tradicional o emprendimiento de negocios, centrado en la creación de valor económico. Frente a este modelo, existe otro tipo de emprendimiento que la literatura ha bautizado como "social", que tiene como objetivo la creación de valor social sostenible (Guzmán \& Trujillo, 2008), que prioriza la creación de valor sobre la apropiación del mismo (Santos, 2009). Debido a su relativa novedad y al hecho de que incluye realidades muy diversas, resulta todavía complejo llegar a un consenso respecto a sus rasgos más característicos.

No obstante, a pesar de estas limitaciones, este fenómeno está adquiriendo una importancia creciente tanto en el campo profesional como en el académico. Su creciente importancia como fenómeno económico se pone de manifiesto con datos como los ofrecidos por Weitzman \& Jalandoni (2002) que señalan como este nuevo tipo de creación de valor ocupaba en 1998 el 4,4\% de las organizaciones estadounidenses, habiendo duplicado su crecimiento entre 1987 y 1997. Según datos del GEM 2009 (Bosma \& Levie, 2009), el índice de emprendimiento social oscila entre el 5,4\% para Dinamarca y el 0,12\% de Guatemala. Santos (2009) señala que el emprendimiento social está en el origen del desarrollo de nuevas industrias, a la vez que permite la validación de nuevos modelos de negocio y dedica recursos a problemas sociales olvidados. Harding (2004), atendiendo a los datos de un estudio realizado en 2003 por el Observatorio de Emprendimiento Global del Reino Unido, señala que "los emprendedores sociales son desproporcionadamente efectivos en la creación de puestos de trabajo" (p. 43).

Respecto a la academia, el emprendimiento social se ha convertido en un tema de creciente interés. Mientras en 2005 se publicaron tan sólo 39 artículos en revistas de máximo impacto, en el 2010 se publicaron 126 , lo que supone un incremento de más de un $300 \%{ }^{3}$

Las dos revistas con mayor índice de impacto dedicas al emprendimiento - Entrepreneurship Theory and Practice y Journal of Business Venturing - han dedicado recientemente números especiales al emprendimiento social, y el Journal of Business Ethics también está preparando un número especial sobre emprendimiento social.

En el marco de las universidades, cabe destacar como ejemplo de la importancia concedida al emprendimiento social el que la Universidad de Oxford cuente con el Skoll Centre for Social Entrepreneurship; la de Duke con el Center for the Advancement of Social Entrepreneurship; la Universidad Nacional de Singapur con el Centre for Social Entrepreneurship y Philanthropy; y que l'École de Commerce essec también cuente con un instituto específico dedicado al emprendimiento social. Otras universidades como la de Harvard o escuelas de negocio como el INSEAD, cuentan con programas dedicados al emprendimiento social que sustentan proyectos de investigación y seminarios, a la vez que son innumerables las universidades que cuentan con cursos específicos dedicados al emprendimiento social (гмв, Babson College; Universidad de Columbia, Berkeley, London Business School, entre otras).

Por otro lado, el emprendimiento social también ha sido reconocido por diferentes autores como una contribución para la sociedad (Alvord, Brown \& Letts, 2002; Dees, 1998; Drayton, 2002; Mair \& Marti, 2006; 
Peredo \& McLean, 2006; Zahra, Gedajlovic, Neubaum \& Shulman, 2009) y un elemento que puede ayudar a resolver necesidades olvidadas por el Estado y por el mercado (Bornstein \& Davis, 2010; Leadbeater, 1997).

No obstante, a pesar del creciente interés por el emprendimiento social, autores como Nicholls (2010) lo consideran todavía como un campo de estudio pre-paradigmático, ya que la mayoría de estudios realizados han sido teóricos o se han basado exclusivamente en la utilización de métodos de análisis cualitativos y existe un escaso nivel de consenso en cuestiones como la propia definición de lo que es una empresa social. Al respecto, Harris, Sapienza \& Bowie (2009) señalan la necesidad de cubrir el espacio vacío de la comparación exhaustiva entre empresas sociales y de negocios pues, aunque existen importantes paralelismos entre las mismas, también abundan las diferencias (Austin, Stevenson \& Wei-Skilner, 2006). Por otro lado, Haugh (2007) y Zahra et al. (2009) señalan la necesidad imperiosa de investigar en relación a los factores de éxito o fracaso de las empresas sociales para evitar los errores que pueden causar su ruina.

Este trabajo pretende atender a las propuestas de los autores anteriormente citados tratando de analizar las principales similitudes y diferencias entre emprendimiento social y de negocios. Más concretamente, se analiza en qué medida afectan a la probabilidad de supervivencia de ambos tipos de emprendimiento, la formación y experiencia del emprendedor así como su motivación para emprender.

Para lograr este objetivo, el artículo se estructura en cinco apartados. En el primero se analizan las similitudes y diferencias entre emprendimiento de negocios y social. En el segundo se estudia el papel que la formación, la experiencia y la motivación pueden jugar como factores explicativos de la superviven- cia. El tercero desarrolla la metodología de análisis, en el cuarto se exponen los resultados y el apartado final recoge las principales conclusiones, limitaciones del estudio y líneas de investigación futura.

\section{Similitudes y diferencias entre el emprendimiento de negocios y el social} Desde la publicación del trabajo de Schumpeter (1942) hasta los trabajos más recientes, como los de Doyle \& Ho (2010) o Roberts \& Woods (2005), el concepto de emprendimiento de negocios ha sido definido por múltiples autores y de formas diferentes. No obstante, se pueden observar notas comunes a muchas de estas definiciones. Entre estas, destacan el énfasis que la mayoría de autores ponen en caracterizarlo como una actividad innovadora y que crea riqueza para el emprendedor.

Por lo que respecta a la condición de actividad innovadora, debe adoptarse una concepción amplia de lo que constituye la innovación, admitiendo como tal los cinco tipos de innovación postulados por Schumpeter (1942): la introducción de un nuevo bien -o la mejora de un bien que ya existía-, la introducción de un nuevo método de producción, la apertura de un nuevo mercado, la conquista de una nueva fuente de suministro de materias primas o bienes en proceso y la creación de un nuevo tipo de organización industrial.

Respecto a la creación de riqueza para los emprendedores, cabe señalar que, para los autores más puristas, la creación de valor económico ha de ser inherente a la actividad en donde no cabe otra clase de valor, sólo el económico. Sin embargo, en la actualidad y desde la perspectiva de la Responsabilidad Social Empresarial (RSE), se exige un mayor nivel de compromiso de las empresas con la sociedad, que vaya incluso más allá de revertir los efectos negativos de la actividad 
económica en su entorno. Por otro lado, la realidad del emprendimiento de negocios parece acercarse mucho más a lo que Kolstad (2007) identifica como una posición neo-friedmaniana, según la cual los gerentes deben desarrollar políticas relacionadas con el emprendimiento social sólo si estas permiten incrementar el retorno de sus accionistas (Guzmán \& Trujillo, 2008).

En el caso del emprendimiento social, no puede decirse que exista en la actualidad un amplio consenso en relación a su definición (Brock, 2008; Light, 2006; Short, Moss \& Lumpkin, 2009). No obstante, también en este caso pueden encontrarse algunas notas comunes a las diferentes definiciones existentes, como son su caracterización como actividad innovadora, característica que comparte con el emprendimiento de negocios, y su orientación a la creación de valor social (Austin et al., 2006; Guzmán \& Trujillo, 2008; Zadek \& Thake, 1997).

Respecto a la innovación, si bien el modelo de Schumpeter (1942) se planteó pensando en la empresa tradicional, es perfectamente aplicable al caso de las empresas sociales. El caso del Grameen Bank, fundado por el premio Nobel de la Paz Muhammad Yunnus, constituye un caso paradigmático en cuya evolución pueden observarse distintos tipos de innovación en el ámbito del emprendimiento social. Yunnus desarrolló un nuevo modelo de banca que llegó a una población que la banca tradicional no atendía, abriendo un nuevo mercado, inicialmente circunscrito a mujeres de Bangladesh con escasos recursos económicos, con el fin de dotarlas de independencia económica y recursos para la puesta en marcha de pequeñas empresas. Yunnus también ha puesto en marcha nuevos métodos de acción para conseguir, por ejemplo, que el índice de morosidad sea el menor posible, concediendo los microcréditos de manera solidaria entre cuatro o cinco clientes y fomentando la colaboración y cooperación entre los mismos (Fogel, Lee \& McCumber, 2011).

Por lo que respecta a la creación de valor social, incluso cuando los autores no lo citan explícitamente, esta creación de valor está presente en sus definiciones, al incluir términos como "servicios sociales" (Reis \& Clohesy, 2001, p. 135), "cambio social transformativo" (Roberts \& Woods, 2005, p. 49) o "compromiso de hacer que las cosas ocurran para ayudar a otros" (Thompson, Alvy \& Lees, 2000, p. 332).

Según la Social Enterprise Knowledge Network-SEKN (2006), la creación de valor social se puede llevar a cabo: a) derribando las barreras que impiden a ciertos colectivos acceder a un bien o servicio al que la mayoría sí puede acceder; b) proporcionando apoyo a poblaciones objetivo debilitadas; c) proporcionando una voz a quien de otra manera no la tendría para la defensa de sus intereses y sus derechos; y d) ofreciendo soluciones a los efectos secundarios indeseados derivados de la producción de bienes o servicios.

En definitiva, la primera conclusión que puede extraerse es que ambos tipos de emprendimiento comparten como característica la innovación, pero difieren en la naturaleza de su misión. No obstante, si bien como se ha señalado anteriormente existen paralelismos entre ambos tipos de emprendimiento en cuanto a los tipos de innovación que incentivan, también aparecen ciertas especificidades propias de cada tipo de emprendimiento. En esta línea, Alvord et al. (2002) señalan que los emprendedores sociales innovan construyendo capacidades locales, atacando una necesidad específica y construyendo movimientos que generen alianzas para oponerse a abusos de las élites e instituciones. 
Por lo que respecta a las principales diferencias entre ambos tipos de emprendimiento, la literatura señala que estos difieren en cuanto a la naturaleza de su misión (Mort, Weerawardena \& Carnegie, 2003). En el emprendimiento de negocios el objetivo es la creación de riqueza (Roberts \& Woods, 2005; Shane \& Venkataraman, 200o), mientras que en el caso del emprendimiento social la creación de riqueza no tiene ningún sentido sin la creación de un valor social (Austin et al., 2006; Guzmán \& Trujillo, 20o8; Zadek \& Thake, 1997). Desde una visión muy restrictiva del fenómeno del emprendimiento social, algunos autores consideran que el lucro es incompatible con el mismo, restringiendo su ámbito de actuación a las organizaciones no lucrativas (Harding, 2004; Lohman, 1989, 1992; Reis, 1999; Thompson, 2002). Otros consideran que la creación de valor social no es incompatible con el lucro, pero tampoco es condición necesaria la existencia del mismo (Arthur, Keenoy, Scott-Cato \& Smith, 2006). Autores como Dorado (2006) y Drayton (2002) señalan que los dos tipos de emprendimiento intentan tener un rendimiento económico y que pueden tener beneficios. En este sentido, Van Slyke \& Newman (2006) señalan que la literatura ofrece múltiples ejemplos de empresas orientadas a la creación de un valor social que tienen beneficios financieros.

A este respecto, Santos (2009) señala que lo realmente relevante y característico del emprendedor social es el énfasis puesto en la creación de valor en todas sus formas, frente al énfasis que el emprendedor de negocios pone en la apropiación de ese valor. La creación de valor supone un aumento de la utilidad de los miembros de la sociedad, una vez descontados los recursos utilizados en la actividad; mientras que la apropiación de valor supone que el emprendedor es capaz de capturar una parte del valor creado mediante la actividad (Mizic \& Jacobson, 2003). Si bien la creación de valor es imprescindible para garantizar una apropiación de valor sostenible y cierta apropiación de valor es imprescindible para asegurar la sostenibilidad y crecimiento de las organizaciones, estas pueden llevar a cabo acciones que incrementan el potencial de apropiación de valor en detrimento de la creación de valor. Por tanto, existe una relación de intercambio o trade-off entre creación y apropiación de valor, y las organizaciones deben elegir dónde poner el énfasis, elección que condicionará su naturaleza y su definición como emprendedor social o de negocios (Santos, 2009).

En este sentido, Massetti (2008) expone que el emprendimiento social puede tener beneficios económicos, pero la diferencia con el emprendimiento de negocios es el uso que se le da a los beneficios. Mientras que en el emprendimiento tradicional los beneficios son usados para enriquecer a los accionistas o dueños de la empresa, en las empresas sociales los beneficios son usados para el soporte de causas sociales. La autora interpreta esta diferencia como grados de intención y describe un continuo donde en un extremo se encuentran las empresas totalmente orientadas al mercado y, en el otro, las empresas totalmente orientadas a fines sociales, pudiendo existir empresas híbridas que combinan fines sociales y lucrativos (ver Gráfico 1).

Una contribución especialmente interesante a la hora de analizar las diferencias entre las empresas sociales y las de negocios es la de Austin et al. (2006), que enmarcan las distinciones existentes en cuatro características fundamentales:

- Fallo del mercado. El fallo del mercado creará diferentes oportunidades para uno y otro emprendimiento. De hecho, un fallo de mercado puede ser una amenaza 
Gráfico 1. Continuo entre misión orientada al mercado y misión social

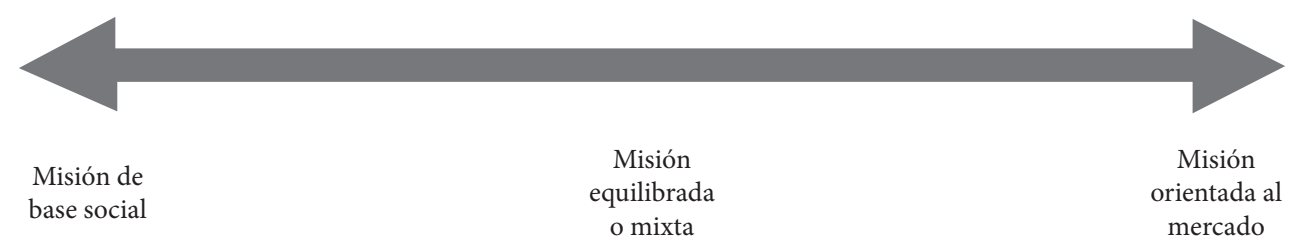

Fuente: De “The Social Entrepreneurship Matrix as a “Tipping Point” for Economic Change”, de B.L. Massetti, 2008, E:CO, 3(10), p. 5.

para el emprendimiento de negocios y una oportunidad para el social. A menudo, el fallo de mercado surge porque aquellos que necesitan un servicio, no pueden pagarlo.

- Misión. La misión en el caso de la empresa de negocios estará focalizada en aspectos relacionados con la competitividad, la creación de valor económico y la rentabilidad a largo plazo. Por el contrario, la misión del emprendimiento social estará centrada en la resolución de algún problema social.

- Movilización de recursos. En referencia a los recursos financieros, un emprendedor de negocios tiene recursos que provienen, fundamentalmente, de la venta del bien o servicio que está ofreciendo. En el caso del emprendedor social, habitualmente, la disponibilidad de recursos depende, en gran medida, de donaciones o subvenciones. Respecto a los recursos humanos, el emprendedor social no suele poder compensar de una manera competitiva a sus trabajadores, especialmente a los más valiosos, dependiendo en mayor medida de compensaciones no monetarias derivadas del propio trabajo para atraer, retener y motivar a sus recursos humanos.

- Medición de los resultados. Para el emprendedor de negocios la medición de sus resultados será fundamentalmente cuantitativa y se utilizarán indicadores económicos y financieros. Por el contrario, para el emprendedor social, la medición de los resultados resulta más compleja, pues es mucho más difícil cuantificarlos y requiere la utilización de variables cualitativas que hagan referencia al cambio social que provoca su actividad.

Por lo que respecta a la figura del emprendedor social o de negocios, parece que la literatura encuentra más similitudes que diferencias entre ellos (Massetti, 2008). Por ejemplo, Hayward, Shepherd \& Griffin (2006), señalan que ambos tipos de emprendedores son apasionados, con empuje, que creen que sus ideas harán del mundo un lugar mejor. Otras de las características que comparten ambas clases de emprendedores son la ambición, el ímpetu (Catford, 1998; Leadbeater, 1997; Thompson et al., 2000), el talento (Bolton \& Thompson, 2000) y la técnica (Thompson et al., 2000). Respecto a sus diferencias, la literatura señala que el emprendedor social se distingue por el deseo de hacer a otros ricos en espíritu o realización (Ligane \& Olsen, 2004), deseo que viene impulsado por una mayor conciencia en el ámbito de la ayuda y la caridad (Thompson, 2002) y una visión que les lleva a tratar de añadir valor a secciones no privilegiadas de la comunidad (Thompson et al., 2000).
2 Formación, experiencia y motivación para emprender como factores explicativos de la supervivencia 2.1 Niveles de supervivencia de las empresas de nueva creación 
Como se ha podido constatar, el emprendimiento social y el de negocios tienen más similitudes que diferencias. Los emprendedores sociales identifican oportunidades de la misma manera que lo hacen los emprendedores de negocios, aunque, en este caso, las oportunidades vienen como soluciones a problemas sociales (Sullivan, 2007). Los emprendedores sociales además, hacen frente a retos similares a los que se enfrentan los emprendedores tradicionales (Massetti, 2008), y utilizan del mismo modo el talento emprendedor para solventar estos problemas (Simms, 2009).

Por ello, autores como Dorado (2006) consideran que la mayoría de las cuestiones de investigación planteadas en el caso del emprendimiento de negocios, resultan también de interés en el caso del emprendimiento social. Entre estas cuestiones, se considera especialmente relevante el comprobar si las empresas sociales son tan sostenibles como las empresas tradicionales, así como mejorar la comprensión de cuáles son las características de los emprendedores y de las empresas sociales que más influencia tienen sobre sus resultados y sus probabilidades de supervivencia. El análisis de supervivencia, opción elegida en el presente trabajo, tiene muchos precedentes en la literatura que considera a la supervivencia como uno de los indicadores más relevantes para determinar el éxito de una empresa (Barney, 1997; Brüderl \& Schüssler, 1990; Cooper, Gimeno-Gastón \& Woo, 1994; Haber \& Reichel, 2005; Van de Ven, Hudson \& Schroeder, 1984).

Según la Teoría del Ciclo de Vida (Churchill \& Lewis, 1983; Mount, Zinger \& Forsyth, 1993) se pueden distinguir tres fases en la vida de la empresa: emergencia, adolescencia y post-adolescencia. Autores como Korunka, Kessler, Frank \& Lueger (2010) señalan que la primera fase es la más arriesgada y en ella adquieren una gran importancia las decisiones del emprendedor. A este respecto, Stinchcombe (1965) acuñó el término "lastre de la novedad" (p. 148) para destacar la existencia de una menor probabilidad de supervivencia de las empresas más jóvenes. Frente a esta hipótesis, Brüderl \& Schüssler (1990) plantean la hipótesis del "lastre de la adolescencia" (p. 530), pues, según estos autores, las tasas de supervivencia son mayores al principio del negocio, pero después, las tasas de mortalidad empiezan a crecer y llegan a un máximo localizado entre los tres y los cuatro años. Este máximo puede variar en función del stock de recursos iniciales con que cuentan las empresas, los que les pueden permitir subsistir durante un tiempo, y del comportamiento racional del emprendedor que le llevará a no abandonar hasta contar con información suficiente para valorar adecuadamente las probabilidades de éxito.

Por lo que respecta a la evidencia empírica, la gran mayoría de los estudios que han analizado la evolución de las empresas de reciente creación han demostrado que el ratio de cierre es bastantes elevado en los primeros años de su existencia. Por ejemplo, Phillips \& Kirchhoff (1989), utilizando datos de Duns \& Bradstreet, encontraron que el $76 \%$ de las nuevas empresas permanecían activas dos años después del inicio de su actividad, el $47 \%$ tras cuatro años y el $38 \%$ a los seis años. Headd (2003), utilizando la base de datos Bits, encontró que el $66 \%$ de las nuevas empresas permanecían abiertas tras dos años, el 49,6\% a los cuatro años y el 39,5\% tras seis años. En Francia, los datos oficiales sitúan la mortalidad de las empresas alrededor del $50 \%$ en los primeros cinco años de existencia (Letowski, 2004). Las autoridades estadounidenses señalan que alrededor del 56\% de las empresas de nueva creación cierran a los cuatro años (Knaup, 2005). En España, la supervivencia a los cuatro años se sitúa alrededor del 53\% (Caneda \& Gar- 
cía, 2008). En conclusión, estas cifras son bastante parecidas, pero cabe preguntarse si las tasas de supervivencia en el caso del emprendimiento social son similares.

En la literatura se pueden encontrar argumentos tanto a favor como en contra de la existencia de una mayor o menor tasa de supervivencia de las empresas sociales. De un lado, Austin et al. (2006) señalan las mayores dificultades que las empresas sociales encuentran a la hora de movilizar recursos financieros y humanos. Los emprendedores sociales suelen depender en mayor medida de subvenciones y donaciones, y suelen tener más dificultades a la hora de conseguir crédito. También, suelen tener ciertas restricciones a la hora de distribuir el excedente, lo que les dificulta el poder ofrecer salarios competitivos a sus empleados, reduciendo sus posibilidades de atraer, retener y motivar empleados talentosos. En consecuencia, esta mayor dificultad de las empresas sociales para conseguir recursos financieros y contar con empleados cualificados, reduciría sus posibilidades de supervivencia.

Por otro lado, la misión de una empresa social es la creación de valor social, mientras que para una empresa de negocios la misión es crear riqueza para el propietario o los shareholders (Austin et al., 2006). Por lo tanto, siguiendo la afirmación de Santos (2009), el menor énfasis en la apropiación de valor económico, podría hacer que las empresas sociales continuaran operando mientras consiguieran generar el capital suficiente para garantizar la supervivencia de la organización. Por el contrario, es altamente probable que una empresa de negocios cese en su actividad en el momento en que los shareholders o propietarios no reciban un nivel adecuado de retorno de la inversión. Además, esta hipótesis es apoyada por Boschee (1995) quien señala que, si una empresa social es el único proveedor de un bien o ser- vicio, la organización continuará trabajando aún sin beneficios, mientras que en el caso de la empresa tradicional, dado que su objetivo es tener beneficios, no tiene ningún sentido continuar con la actividad, incluso si esta empresa es la única proveedora de un bien o servicio. Una vez revisados estos argumentos, se propone la siguiente hipótesis:

Hipótesis 1 (H1). Las empresas de interés social presentan similares ratios de supervivencia que las puramente de negocios, o lo que es lo mismo, no existen diferencias significativas en los niveles de supervivencia en función del tipo de empresa, social o de negocios.

\subsection{El perfil del emprendedor como factor de} éxito de las empresas sociales y de negocios Otra cuestión de investigación relevante es si los factores de éxito del emprendimiento de negocios juegan el mismo papel en el emprendimiento social. Respecto a los factores de éxito de las empresas tradicionales o de negocios, la literatura destaca tres grupos de factores o variables: factores ligados al perfil del emprendedor (Bosma, Van Praag \& de Wit, 200o; Sapienza \& Grimm, 1997); factores ligados a las características de la empresa, entre los que destacan estudios relacionados con el tamaño de la empresa, el sector y la estrategia (Agarwal \& Audretsch, 2001; Dunne \& Hughes, 1994; Fritsch, Brixy \& Falck, 2006); y factores ligados al entorno competitivo, caso en el que la investigación se ha centrado en el estudio de las condiciones del mercado y la competencia.

Por lo que respecta al análisis del primer grupo de factores, los relacionados con el perfil del emprendedor, en el cual se enmarca el presente artículo, las variables más estudiadas han sido la edad del emprendedor (Bosma et al., 2000), el género (Verheul \& Thurik, 2000), la formación (Schiller \& Crewson, 1997), la experiencia previa a la 
constitución del negocio (Reuber \& Fisher, 1999) y la motivación para emprender (Van Praag, 2003).

El presente estudio analiza dos variables que miden elementos del capital humano del emprendedor, la formación y la experiencia, y una variable relacionada con las características psicológicas del emprendedor, la motivación para emprender. En general, las investigaciones realizadas han demostrado que estas variables están positiva y significativamente relacionadas con la supervivencia de las empresas de negocios. En el caso de la motivación, la oportunidad frente a la necesidad supone un mejor predictor de la supervivencia. Pero, ise mantienen estas relaciones en el caso de las empresas sociales?, y, más concretamente, ¿juegan la formación, la experiencia y la motivación para emprender el mismo papel en el caso de la supervivencia del emprendimiento social? En los siguientes párrafos se tratarán estas cuestiones y se plantearán hipótesis al respecto.

Por lo que respecta a la formación y la experiencia, un número considerable de estudios señalan que constituyen dos de los factores más importantes a la hora de explicar los resultados de una nueva empresa (Agarwal, Echambadi, Franco \& Sarkar, 2004; Brüderl, Preisendörfer \& Ziegler, 1992; Evans \& Leighton, 1989; Gimeno, Folta, Cooper \& Woo, 1997; Headd, 2003; Klepper, 2002; Klepper \& Simons, 2000; Mitchell, 1989).

Respecto a la formación, existen diferentes propuestas sobre cómo la formación de un emprendedor puede ayudar a sobrevivir a una empresa. En este sentido, Honig (1998) y West \& Noel (2009) consideran que el conocimiento mejora la habilidad de gestión para el desarrollo de un negocio. Por otro lado, Castrogiovanni (1996) opina que el conocimiento puede ayudar al propietario a evaluar mejor las oportunidades, así como a utilizar los recursos de forma más eficiente. Para Haber \& Reichel (2005) el conocimiento beneficia la adquisición y transformación del know-how.

Pero, ¿qué tipo de formación es la realmente relevante? Según el economista clásico Jean Baptiste Say (1803; citado por Van Praag, 2003), un emprendedor necesita "juicio, perseverancia y conocimiento del mundo así como del negocio" (p. 330). Por lo tanto, se puede decir que para comenzar un negocio y esperar buenas tasas de supervivencia, son necesarios dos tipos de conocimiento, específico y general, lo que suscita una pregunta adicional, ¿es un tipo de conocimiento más importante que otro?

Distintos autores ponen el énfasis en el conocimiento específico. Entre ellos, Haber \& Reichel (2005) señalan que este conocimiento específico puede mejorar los resultados de un negocio debido a que permite el perfeccionamiento de la capacidad de gestión, por lo que puede ayudar a desarrollar un plan o negocio mejor. Además, según Castrogiovanni (1996), el conocimiento específico ayudará a detectar las necesidades de los clientes y utilizar los recursos más eficientemente, permitiendo a las empresas reducir sus costes por debajo de los de sus competidores. También, Ribeiro \& Castrogiovanni (2012) apoyan estas hipótesis y sus resultados indican la existencia de una relación positiva entre conocimiento específico, rentabilidad y productividad.

A priori, en virtud de las similitudes y diferencias entre emprendimiento social y de negocios previamente comentadas y teniendo en cuenta el tipo de beneficios que derivarían de un mayor nivel de formación general o específica, los argumentos que se acaban de exponer parecen resultar tan válidos para un tipo de emprendimiento como para el otro. Por ello, se plantean las siguientes hipótesis: 
Hipótesis 2A (H2A). Existe una relación positiva y significativa entre la formación del emprendedor y la supervivencia tanto de las empresas de interés social, como de las de negocios.

Hipótesis $2 \mathrm{~B}(\mathrm{H} 2 \mathrm{~B})$. La relación entre la formación y las tasas de supervivencia es, en ambos casos, más fuerte en el caso de la formación específica que en el caso de la formación general.

En relación a la experiencia, según Ribeiro \& Castrogiovanni (2012), ésta permite la mejor identificación, adquisición y explotación de recursos. Sus resultados señalan que la experiencia previa en la misma industria está positivamente relacionada con la productividad pero no con la rentabilidad. Van Praag (2003) considera que no toda la experiencia tiene un efecto positivo y significativo en el éxito del negocio. De hecho, su estudio muestra cómo la experiencia previa como emprendedor en un negocio diferente, no afecta significativamente al éxito del negocio actual, mientras que la experiencia en el mismo sector sí tiene una correlación positiva con el éxito del negocio.

Sobre la experiencia en los equipos de dirección o management teams, Sheperd (1999) señala que la supervivencia es más alta en las empresas en las que el equipo de dirección tiene experiencia en la misma industria. Dencker, Gruber \& Shah (2009) muestran cómo la experiencia y el conocimiento previo están relacionados positivamente con la supervivencia de las empresas, moderando los efectos de las actividades de aprendizaje subsiguientes. En consecuencia y sobre la base de los mismos argumentos expuestos en el caso de la formación, se plantea la siguiente hipótesis:

Hipótesis 3 (H3). Existe una relación positiva y significativa entre la experiencia en el nego- cio del emprendedor y la supervivencia tanto de las empresas de interés social, como de las de negocios.

En relación a la motivación para iniciar el negocio, la literatura distingue entre dos tipos de emprendedores: los de oportunidad y los de necesidad. En el primer caso, el emprendedor inicia la actividad porque encuentra una oportunidad en el mercado que puede ser rentable. En el segundo caso, el emprendedor inicia la actividad como un último recurso para evitar el desempleo (Reynolds, Camp, Bygrave, Autio \& Hay, 2001); es decir, los emprendedores de oportunidad están movidos por la búsqueda de la independencia, la autonomía y la vocación de poner en marcha su propio negocio, mientras que los emprendedores por necesidad no están interesados en el negocio, sólo en trabajar. A este respecto puede plantearse un paralelismo con las empresas sociales, pues no se puede descartar la existencia de dos tipos de emprendedores sociales, los que tienen una verdadera vocación de servicio, de crear valor para la sociedad, y los que ven estas empresas como un medio para conseguir una ocupación y/o satisfacer sus propias necesidades.

Los resultados obtenidos por Headd (2003) indican que las tasas de supervivencia de las empresas de negocio creadas por los emprendedores por oportunidad, que él denomina por razones personales, son mayores que para el caso de los negocios iniciados por otras razones. Ello coincide con el GEM, que señala que este tipo de emprendedores tienen mayores tasas de supervivencia (Reynolds et al., 2001). Siguiendo a Headd (2003) y a Van Praag (2003), esto ocurre porque cuando un emprendedor por necesidad encuentra otro trabajo, generalmente, liquidará su compañía; sin embargo, un emprendedor de oportunidad, conti- 
nuará con el negocio mientras éste consiga mantenerse a flote.

Otra de las razones para explicar las mayores tasas de supervivencia la ofrecen Ho \& Wong (2007), al señalar que los emprendedores por oportunidad son más innovadores y que, por lo tanto, se puede esperar que sus tasas de supervivencia sean mayores por la puesta en marcha de un negocio que ofrece algo diferente o que fabrica de una manera más eficiente. En consecuencia, se formula la siguiente hipótesis:

Hipótesis $4\left(\mathrm{H}_{4}\right)$. La probabilidad de supervivencia tanto de empresas de interés social como de las puramente de negocios, es mayor si la motivación para emprender es la oportunidad que si es la necesidad.

\section{Metodología}

En virtud de la colaboración con el Servicio de Gestión y Planificación de Programas del Instituto Valenciano de la Juventud IVAJ), en el marco del Programa de Ayuda a la Creación de Empresas por Jóvenes Emprendedores, se obtuvieron datos de $2.179^{4}$ empresas creadas entre 2000 y 2003 , de las cuales 227 son actividades de interés social.

Si bien se recibieron 2.833 solicitudes, en el estudio se consideraron únicamente las empresas aceptadas y evaluadas, ya que la información de las rechazadas era muy limitada. La colaboración se ha centrado en la evaluación de los proyectos presentados por jóvenes emprendedores que optaban a subvención y el posterior seguimiento de su evolución. La información utilizada se ha obtenido de las memorias de proyectos presentados a subvención, de las memorias anuales de ejecución del Programa anteriormente citado y del seguimiento realizado a las empresas creadas por medio de las bases

4 Cuatro empresas de negocios fueron eliminadas debido a carencias en la información obtenida. de datos de las Cámaras de Comercio de Alicante, Castellón y Valencia. A continuación se describen las variables del modelo.

\section{Variables dependientes}

- Supervivencia en $t+3$ : variable dicotómica que indica si la empresa sobrevive o no a los tres años de constitución de la empresa; es decir, para medir esta variable se comprobó si la empresa seguía activa el tercer año posterior al de su creación.

- Supervivencia en $t+6$ : variable dicotómica que indica si la empresa sobrevive o no a los seis años de constitución de la empresa. $\mathrm{Al}$ igual que en el caso anterior, se comprobó si la empresa seguía activa el sexto año posterior a su creación.

Para distinguir entre empresas puramente de negocios y sociales se utilizaron dos variables de clasificación:

- Tipo de empresa: variable dicotómica que expresa si la empresa es puramente de negocios o se trata de una empresa social.

- Grado de interés social: variable categórica que mide el grado de interés social de la empresa. El interés social de la empresa se mide en una escala Likert que va de o a 5 grados. Las empresas de grado cero (o) son empresas puramente de negocios, por el contrario las empresas de grado cinco (5) son puramente sociales. Los grados intermedios indican hasta qué punto prima la misión social de la empresa sobre los objetivos económicos. ${ }^{5}$ Esta clasificación por niveles del grado de interés social se ha basado en el continuo previamente comentado por Massetti (2008).

5 Según los criterios del Instituto Valenciano de la Juventud, se considera una empresa de interés social a aquella que se dedique a actividades que promuevan la igualdad de oportunidades (integración), la mejora del medio ambiente, la innovación tecnológica, la innovación organizativa, la educación y formación para la integración o la cooperación empresarial (Diario Oficial de la Comunidad Valenciana-DOCV, 2007). 


\section{Variables independientes}

- Nivel de formación: variable categórica que recoge cuatro niveles de formación (1. estudios primarios, 2. ESO+FPI, ${ }^{6} 3$. FPII+Bachiller, 4. estudios universitarios).

- Formación afín: variable dicotómica que indica si el emprendedor tiene algún tipo de formación específica relacionada con el negocio.

- Experiencia afín: variable dicotómica que indica si el emprendedor tiene al menos un año de experiencia laboral específica relacionada con el negocio.

- Motivación para emprender: variable dicotómica que señala si se trata de un emprendimiento por oportunidad o necesidad. Para determinar si el emprendimiento es por oportunidad o necesidad se ha basado en la situación laboral previa del o de los promotores. Si el promotor (o al menos del $75 \%$ de los promotores si son varios) parte de una situación de empleo estable por cuenta propia o ajena, se considerará que se trata de un emprendimiento por oportunidad, si no se cumple este requisito se considerará emprendimiento por necesidad.

\section{Variables de control}

- Plantilla: número de empleados totales incluyendo promotores del negocio.

- Capital inicial: proxy del capital inicial, capital subvencionable según los criterios del Servicio de Gestión y Planificación de Programas del IVAJ.

- Sector: variable dicotómica con valores 1 industria y cero (o) servicios.

6 Eso: Educación Secundaria Obligatoria. Hace referencia al último tramo de la educación obligatoria gratuita, este ciclo consta de 4 cursos y cubre hasta los 16 años del alumno/a. FP: Formación Profesional. Hace referencia a la enseñanza postobligatoria orientada a la capacitación de los alumnos/as para el desempeño cualificado de distintas profesiones. Se divide en dos grados: FPI (Formación Profesional I o grado medio) y FPII (Formación Profesional II o grado superior).
- Año: año de inicio de la actividad.

Cabe significar que los valores asignados a las variables actividad de interés social, formación afín y experiencia afín han sido fijados por los expertos evaluadores del programa del IVAJ. Para evitar posibles sesgos del evaluador y aumentar la fiabilidad de las valoraciones, se ha procedido cada año a seleccionar una pequeña muestra de empresas que ha sido valorada sucesivamente por los distintos evaluadores. A continuación, se han analizado cada año las discrepancias encontradas, resuelto las dudas y unificado los criterios a utilizar en la evaluación. Las demás variables son variables objetivas obtenidas de los propios emprendedores y las Cámaras de Comercio.

\section{Metodología de análisis estadístico}

Dada la naturaleza de las variables dependientes (supervivencia en $t+3$ y $t+6$ ), se ha optado por utilizar la prueba $\chi^{2}$ de Pearson, la prueba de Mann-Whitney para dos muestras independientes y el modelo multivariante logístico o modelo logit. El nivel de significancia empleado en todos los análisis ha sido el $5 \%(\alpha=0,05)$, lo cual significa que si el p-valor resultante de la prueba es menor a 0,05 existirán diferencias significativas entre las dos muestras que se analizan, empresas sociales y empresas de negocios.

Las técnicas de análisis bivariante permiten identificar las variables que individualmente tienen capacidad explicativa en relación a la supervivencia de las empresas. Así, la Prueba $\chi^{2}$ de Pearson se ha utilizado como prueba de asociación o dependencia entre la supervivencia a los tres y seis años y otras variables categóricas, siempre que la frecuencia esperada de las celdas en la tabla de contingencia fuera superior a cinco casos. En caso contrario, y sólo para variables dicotómicas, se ha utilizado la prueba exacta de Fisher. La prueba de Mann-Whitney para 
dos muestras independientes se ha utilizado para contrastar si la distribución de un parámetro, cuando menos ordinal, es o no la misma en dos muestras independientes.

Bajo el objetivo de completar el análisis bivariante previo, se ha estimado un modelo de regresión logística, que estima la relación $\mathrm{o}$ asociación entre dos variables teniendo en cuenta que puede haber otros factores que modifiquen esa relación. Este modelo logit expresa la probabilidad de no sobrevivir en función de una serie de variables independientes. El modelo logístico expresa el odd $s^{7}$ como función exponencial de las variables independientes:

$$
\frac{p}{1-p}=e^{\beta_{0+\beta_{1} X_{1}+\beta_{2} X_{2}}}
$$

Donde $p$ es la probabilidad de no sobrevivir y $X_{i}(i=1,2)$ son las variables independientes (formación, experiencia, etc.). Los $\beta_{i}$ son los coeficientes de regresión a estimar en el análisis. Se debe notar que una manera equivalente de escribir la Ecuación 1 es:

$$
\frac{p}{1-p}=e^{\beta_{0}} e^{\beta_{1} X_{1}} e^{\beta_{2} X_{2}}
$$

De este modo, es fácil ver que el aumento unitario de un determinado factor $X_{i}$, multiplica el odds por el valor $e^{\beta i}$, por tanto, la influencia significativa de un factor se va a medir en términos de variación producida en el odds de la no supervivencia. El modelo de entrada de variables ha sido por pasos condicional hacia delante, con un p-valor de entrada de 0,05 y de salida de 0,1 para las variables, lo cual significa que si el pvalor es menor a 0,05 existe una relación significativa entre la variable dependiente e independiente que se está midiendo, por

7 El odds es la razón entre la probabilidad de no sobrevivir y la probabilidad de sobrevivir. el contrario, si es mayor indica ausencia de relación.

El signo de esa relación viene determinado por Beta $(\beta)$, si el signo es positivo significa que cuanto más aumenta la variable en cuestión, variable independiente, más aumentan las probabilidades de fracaso, es decir, más aumenta el riesgo de no sobrevivir. Respecto a la bondad del ajuste, se ha utilizado el estadístico menos dos veces el logaritmo neperiano de la verosimilitud (-2LL), y el coeficiente $R^{2}$ de Nagelkerke. Paralelamente, la prueba de Hosmer y Lemeshow contrasta la calibración del modelo, esto es, el grado en que la probabilidad pronosticada se ajusta a la realidad.

\section{Resultados}

Como ya se ha señalado, de las 2.175 empresas analizadas, 227 presentan algún grado de interés social, si bien sólo 52 de ellas pueden considerarse como puramente empresas sociales. El 16,4\% de las empresas fueron creadas en el año 2000, el 21,2\% en 2001, el $29,4 \%$ en 2002 y el $33,1 \%$ restante en 2003 . La muestra está compuesta por empresas pequeñas, con una plantilla total que oscila entre 1 y 142 empleados (incluidos los propios emprendedores), siendo la media de 2,04 empleados. El capital subvencionable (proxy del capital invertido) oscila entre los EUR $\$ 100$ y los EUR $\$ 970.000$, con una media de EUR \$31.204. La mayoría de las empresas son empresas de servicios, concretamente el 89,7\%. El 58,0\% de los emprendedores lo son por oportunidad y el restante $42,0 \%$ por necesidad, el 6o,8\% cuenta con formación afín y el $69,4 \%$ con experiencia afín. Respecto al nivel de formación, el 14,7\% cuenta con estudios primarios, el 13,9\% con estudios a nivel ESO+FPI, el 25,5\% con estudios a nivel de FPII+Bachiller y $45,9 \%$ con estudios universitarios. ${ }^{8}$

8 Los porcentajes se han calculado sobre los casos válidos. 
Virginia Simón Moya, Lorenzo Revuelto Taboada \& 4.1 Supervivencia según el tipo de empresa Un $72,0 \%$ del total de empresas sobrevive a los tres años mientras que a los seis años este porcentaje se reduce al 52,0\%. La tasa de supervivencia de las empresas de negocios es ligeramente superior a los tres años $(72,2 \%$ frente a $68,7 \%$ ) mientras que, a los seis años sobreviven más las empresas de carácter social $(55,1 \%$ frente a $52,1 \%)$. No obstante, los resultados de la $\chi^{2}$ de Pearson indican que estas diferencias no son significativas ni a los tres años ( $\mathrm{p}$-valor $=0,266>0,05)$, ni a los seis años ( $\mathrm{p}$-valor $=0,345>0,05)$. Cuando se tiene en cuenta el grado de interés social de las empresas, tampoco parece existir una relación clara entre el mismo y la probabilidad de sobrevivir. Los resultados de la prueba de Mann-Whitney de comparación de distribuciones para muestras independientes, indican que no existen diferencias significativas en la supervivencia según el grado de interés social ni a los tres años ( $\mathrm{p}$ valor $=0,375)$, ni a los seis años a $(\mathrm{p}$-valor $=$ o,241). Por tanto, queda validada la hipótesis 1 al no existir diferencias significativas en la probabilidad de sobrevivir en función del tipo de empresa.

\subsection{Influencia de la formación y la experiencia del emprendedor en la supervivencia}

La influencia de estos factores ha sido analizada por medio de regresiones logísticas, una para la supervivencia en $t+3$ y otra para la supervivencia en $t+6$. Estos modelos logit expresan la probabilidad que tiene una empresa de no sobrevivir en función de los factores considerados, es decir, las variables independientes.

El modelo logit aplicado en $t+3$ muestra que, en el caso de las empresas sociales, ninguna de las variables independientes consideradas resulta significativa; es decir,

Cabe considerar que existe un considerable porcentaje de valores perdidos en algunas de estas variables que oscila entre el $7 \%$, en el caso de la experiencia afín, y el $22 \%$, en el caso del nivel de formación. según los resultados obtenidos, la probabilidad de sobrevivir de una empresa no está significativamente relacionada con el grado de formación, ni con la formación y/o experiencia afín o relacionada del emprendedor, anteriores a la constitución del negocio.

En cambio, en el caso de las empresas de negocios, los resultados del modelo logit en $t+3$ muestran que el éxito de las empresas de negocios sí se ve afectado significativamente, tanto por la formación como por la experiencia del emprendedor. En ambos casos, la formación o experiencia del emprendedor reducen la probabilidad de no sobrevivir. Ello se puede constatar al observar en la Tabla 1 la columna variación del riesgo, que indica el porcentaje en que aumenta o se reduce la probabilidad de no sobrevivir con la introducción de la variable independiente, y la columna Beta $(\beta)$, que muestra el signo de la relación. Los Beta negativos indican que la introducción de las variables reduce la probabilidad de no sobrevivir en $t+3$, en el porcentaje establecido en la columna variación del riesgo. ${ }^{9}$

Del análisis de resultados se puede extraer que todas las categorías de formación reducen el riesgo de no sobrevivir, ya que los signos de las Betas son negativos, sin embargo, al contrario de lo que sería lógico de pensar, el riesgo no disminuye conforme aumenta el nivel de formación. El nivel de formación que más reduce la probabilidad de no sobrevivir es el segundo, ESO+FPI, que la reduce un 57,6\% (p-valor $=0,000)$, frente al 30,3\% de la categoría FPII+Bachiller ( $\mathrm{p}$-valor = o,045), o el 37,4\% de la categoría estudios universitario ( $\mathrm{p}$-valor $=0,005$ ). Cabe destacar, asimismo, que la variable formación afín o relacionada con el negocio no ha entrado en el modelo, lo que significa que no ha mostrado una relación significativa con las probabilidades de no sobrevivir.

9 El riesgo no ha sido calculado para la categoría "Primarios +EGB", ya que ésta se ha tomado como categoría de referencia. 
Tabla 1. Resultados modelo logit en $t+3$ para emprendedores de negocios

\begin{tabular}{|c|c|c|c|c|c|c|c|}
\hline \multirow{2}{*}{ Paso 2 (2) } & \multirow{2}{*}{$\begin{array}{c}\text { Variación del } \\
\text { riesgo }\end{array}$} & \multirow{2}{*}{ в } & \multirow{2}{*}{ E.T. ${ }^{(a)}$} & \multirow{2}{*}{ Sig. } & \multirow{2}{*}{$\operatorname{EXP}(B)^{(b)}$} & \multicolumn{2}{|c|}{ I.C. $95,0 \%$ para $\exp (\text { B })^{(\mathrm{c})}$} \\
\hline & & & & & & Inferior & Superior \\
\hline $\begin{array}{l}\text { Primarios+EGB }{ }^{(\mathrm{d})} \\
\text { (categoría de refer- } \\
\text { encia) }\end{array}$ & & & & 0,001 & & & \\
\hline $\mathrm{ESO}+\mathrm{FPI}$ & $57,600 \%$ & $(0,859)$ & 0,224 & - & 0,424 & 0,273 & 0,658 \\
\hline FPII+Bachiller & $30,300 \%$ & $(0,360)$ & 0,180 & 0,045 & 0,697 & 0,490 & 0,993 \\
\hline Universitarios & $37,400 \%$ & $(0,468)$ & 0,167 & 0,005 & 0,626 & 0,452 & 0,868 \\
\hline Experiencia & $38,0 \%$ & $(0,476)$ & 0,131 & - & 0,621 & 0,481 & 0,803 \\
\hline Constante & & $(0,209)$ & 0,161 & 0,195 & 0,811 & & \\
\hline
\end{tabular}

Nota. 1. Variable(s) introducida(s) en el paso 1: Experiencia., 2. Variable(s) introducida(s) en el paso 2: Nivel de Formación. (a) E.T. es el error tipificado asociado al Beta. (b). El Exp(Beta) se interpreta como riesgo asociado a la variable de coeficiente Beta. (c) IC. es el intervalo de confianza para Exp(Beta). (d) EGB. Educación General Básica.

Por lo que respecta a la relación entre la experiencia previa afín o relacionada del emprendedor y el riesgo de fracaso de las empresas, el modelo indica que la relación es significativa ( $p$-valor $=0,000$ ), y que al contar con este tipo de experiencia, se reducen las probabilidades de no sobrevivir en un $38 \%$.

Respecto a las variables de bondad del ajuste, el valor de -2LL es 1.610,5 en el primer paso y 1.594,4 en el segundo. La significancia para el contraste de Hosmer-Lemeshow es 0,999; lo que permite aceptar la hipótesis nula de que el modelo es adecuado. Sin embargo, el valor de la $\mathrm{R}^{2}$ de Nagelkerke indica que las variables independientes consideradas sólo explican un 3,1\% de la varianza de la variable dependiente, en este caso supervivencia en $t+3$. En consecuencia, existen otros factores, probablemente más relevantes, que determinan el éxito o fracaso de las empresas.

Pasando ahora a analizar los resultados del modelo logit en $t+6$, cabe destacar que, al igual que en el caso anterior, en el caso de las empresas sociales las variables independientes no han mostrado ninguna relación significativa con las probabilidades de éxito o fracaso de las mismas. Por el contrario, sí que se han observado relaciones significativas para el caso de las empresas de negocios. En este caso, el modelo para $t+6$ sólo incluye la formación afín ( $\mathrm{p}$-valor $=0,000)$ y la experiencia afín $(p$-valor $=0,000)$ como variables significativas, quedando fuera, en este caso, el nivel de formación alcanzado. El riesgo de no sobrevivir a los seis años se reduce a un $44,1 \%$ entre los empresarios con formación afín frente a los que no la tienen, y a un $41,5 \%$ entre los empresarios con experiencia afín también frente a los que no la tienen (ver Tabla 2).

En este caso, los valores de -2LL, 1.863,3 en el primer paso y 1.844,4 en el segundo, la $\mathrm{R}^{2}$ de Negelkerke 0,051 y de la significancia para el contraste de Hosmer-Lemeshow, 0,999, también indican que el modelo es adecuado pero que existen otros factores determinantes de la probabilidad de no sobrevivir no incluidos en el modelo.

Por lo tanto, del análisis de los resultados se pueden extraer algunas conclusiones interesantes. La primera de ellas es que, tal y como ya había demostrado la literatura, el capital humano aportado por el emprendedor, en este caso la formación y experiencia, muestran una relación positiva y significativa con las tasas de supervivencia de las 
empresas de negocios. Sin embargo, estas relaciones no se cumplen para las empresas sociales. Por tanto las hipótesis H2A y H3, que planteaban la existencia del mismo tipo de relación para ambos tipos de empresa, no se validan. Por lo que respecta a la hipótesis H2B, tampoco se cumple para el caso de las empresas sociales. En el caso de las de negocios, no se puede establecer cuál de las dos variables de formación tiene una mayor influencia sobre la supervivencia puesto que, en este caso, los resultados en $t+3$ y $t+6$ divergen. Sería necesario analizar en profundidad las interdependencias entre estas y otras variables para poder establecer con mayor claridad el efecto de la formación.

\subsection{Supervivencia según la motivación para emprender}

La proporción de empresas que sobreviven en $t+3$ y $t+6$ es superior cuando la motivación para emprender es la oportunidad que cuando es la necesidad, tanto a nivel global, como para los emprendedores de negocios y las empresas con algún grado de interés social (ver Tabla 3). A nivel global, los resultados de la prueba $\chi^{2}$ de Pearson son significativos tanto a los tres años (p-valor $=0,000)$ como a los seis años (p-valor $=$ 0,000 ). Si se calcula los odds ratio, a los tres años el riesgo relativo de no sobrevivir es 1,5 veces mayor entre los emprendedores por necesidad que por oportunidad, y a los seis años el riesgo es casi el doble $(1,8)$.

Por tipo de empresa, las pruebas estadísticas muestran que, en el caso del emprendimiento de negocios, el patrón global se mantiene ( $\mathrm{p}$-valor $=0,000$; tanto en $t+3$ como en $t+6$ ). Por el contrario, en el caso de las empresas con algún grado de interés social, no se puede afirmar la existencia de diferencias significativas ni a los tres años ( $\mathrm{p}$-valor $=0,301)$, ni a los seis años (p-valor $=0,319$ ). En el caso de las empresas de negocios, el riesgo de cerrar a los tres años es 1,6 veces superior entre los empresarios por necesidad y a los seis años, es casi el doble $(1,9)$.

Tabla 2. Resultados modelo logit en $t+6$ para emprendedores de negocios

\begin{tabular}{lccccccc}
\hline Paso 2(2) & $\begin{array}{c}\text { Variación del } \\
\text { riesgo }\end{array}$ & в & E.T. ${ }^{(\text {a) }}$ & Sig. & EXP $(\text { в })^{(\text {b) }}$ & \multicolumn{2}{c}{ I.C. 95,0\% para EXP(B) $)^{(\mathrm{c})}$} \\
\hline Formación & $44,1 \%$ & $(0,581)$ & 0,118 & 0,000 & 0,559 & 0,444 & Superior \\
Experiencia & $41,5 \%$ & $(0,536)$ & 0,126 & 0,000 & 0,585 & 0,457 & 0,748 \\
Constante & & 0,690 & 0,122 & 0,000 & 10,994 & & \\
\hline
\end{tabular}

Nota. 1. Variable(s) introducida(s) en el paso 1: Experiencia., 2. Variable(s) introducida(s) en el paso 2: Formación afín (a) E.T. es el error tipificado asociado al Beta. (b). El Exp(Beta) se interpreta como riesgo asociado a la variable de coeficiente Beta. (c) IC. es el intervalo de confianza para $\operatorname{Exp}($ Beta).

Tabla 3. Supervivencia según la motivación para emprender en porcentaje

\begin{tabular}{lcccccc}
\hline & \multicolumn{2}{c}{ Total empresas } & \multicolumn{2}{c}{ Emprendedor negocios } & \multicolumn{2}{c}{ Emprendedor social } \\
\cline { 2 - 6 } & Necesidad & Oportunidad & Necesidad & Oportunidad & Necesidad & Oportunidad \\
\hline No sobrevive $t+3$ & 31,3 & 22,8 & 31,2 & 22,5 & 32,2 & 25,6 \\
Sobrevive $t+3$ & 68,7 & 77,2 & 68,8 & 77,5 & 67,8 & 74,4 \\
No sobrevive $t+6$ & 53,5 & 38,0 & 54,2 & 37,8 & 47,0 & 40,0 \\
Sobrevive $t+6$ & 46,5 & 62,0 & 45,8 & 62,2 & 53,0 & 60,0 \\
\hline
\end{tabular}


En función de estos resultados, cabe señalar que no existe evidencia suficiente de que en el caso de las empresas sociales, la motivación para emprender esté relacionada con diferencias en la probabilidad de sobrevivir, por lo que se debe rechazar la hipótesis 4. Cabe señalar, no obstante, que con un tamaño muestral de $227 \mathrm{em}$ presas de interés social, para una potencia estadística aceptable del $80 \%$, la diferencia mínima entre proporciones que detecta la prueba $\chi^{2}$ de Pearson es del $10 \%$, por lo que el tamaño muestral puede estar limitando la posibilidad de encontrar diferencias estadísticamente significativas.

\subsection{Influencia de las variables de control en la supervivencia de la empresa}

Se decidió introducir en los modelos logit, como variables de control, las variables año de creación, sector de actividad, número de empleados estables y capital inicial, consi- deradas relevantes por la literatura a la hora de explicar la supervivencia, para constatar si la introducción de estas variables de control aumentaba la capacidad explicativa del modelo y podría afectar de algún modo a las relaciones entre formación, experiencia, motivación para emprender y supervivencia. Al introducir, paso a paso, en los modelos de regresión logística las variables de control consideradas en el trabajo, se puede observar cómo aumenta la proporción de varianza explicada ${ }^{10}$, es decir, la capacidad explicativa del modelo (ver Tabla 4).

En la Tabla 4 se observa que en $t+3$ para las empresas de negocios, el modelo aumenta su capacidad explicativa cuando se introducen las variables formación, experiencia, capital y plantilla, llegando estas variables a aumentar la capacidad explicativa del modelo hasta un $8,1 \%$. Siguiendo con las empresas de negocios, 10 La máxima capacidad explicativa de un modelo correspondería a un valor de la $\mathrm{R}^{2}$ de Nagelkerke de 1 .

Tabla 4. Influencia de las variables de control consideradas

\begin{tabular}{|c|c|c|}
\hline & \multicolumn{2}{|c|}{$\mathrm{R}^{2}$ de Nagelkerke } \\
\hline & $\begin{array}{l}\text { A los } 3 \text { años de } \\
\text { supervivencia }\end{array}$ & $\begin{array}{l}\text { A los } 6 \text { años de } \\
\text { supervivencia }\end{array}$ \\
\hline \multicolumn{3}{|l|}{ Empresas de negocios } \\
\hline Modelo con formación y experiencia & 0,031 & 0,051 \\
\hline Modelo con formación y experiencia + sector & - & 0,062 \\
\hline Modelo con formación y experiencia + motivación & 0,040 & 0,071 \\
\hline Modelo con formación y experiencia + capital & 0,048 & 0,075 \\
\hline Modelo con formación y experiencia + plantilla & 0,074 & 0,107 \\
\hline $\begin{array}{l}\text { Modelo con formación y experiencia + moti- } \\
\text { vación+ capital + plantilla }\end{array}$ & $\begin{array}{l}\text { 0,081 (se excluye } \\
\text { la motivación) }\end{array}$ & Más sector: 0,130 \\
\hline \multicolumn{3}{|l|}{ Empresas de interés social } \\
\hline Modelo con formación y experiencia & - - (Modelo no converge $)$ & —— (Modelo no converge) \\
\hline Modelo con formación y experiencia + capital & 0,130 & 0,061 \\
\hline Modelo con formación y experiencia + plantilla & 0,143 & 0,082 \\
\hline $\begin{array}{l}\text { Modelo con formación y experiencia }+ \text { capital }+ \\
\text { plantilla }\end{array}$ & 0,185 & 0,122 \\
\hline
\end{tabular}


se observa que en $t+6$ el modelo que mejor explica la supervivencia de las empresas es aquel en el que se introducen las variables formación, experiencia, motivación, capital, plantilla y sector $\left(\mathrm{R}^{2}=13 \%\right)$.

Respecto a las empresas sociales, de la Tabla 4 se puede extraer la conclusión que si bien formación, experiencia y motivación no resultan significativas, sí lo son las variables capital y plantilla. Al introducir estas variables, la capacidad explicativa del modelo es de un $18,5 \%$ en $t+3$ y de un $12,2 \%$ en $t+6$.

El hecho que estas variables estén positivamente relacionadas con el éxito o supervivencia de las empresas sociales cobra especial interés pues, como pudo verse en el apartado primero, la literatura destaca como uno de los principales hándicaps de las empresas sociales, las dificultades que encuentran a la hora de movilizar recursos tanto humanos como financieros. La gran influencia de estas variables en sus probabilidades de supervivencia podría estar dejando un papel muy secundario a otras variables como las analizadas (formación, experiencia y motivación para emprender).

No sorprende que el año de creación de la empresa no haya resultado ser un factor significativo, ni para el emprendimiento social ni el de negocios, en la medida en que el periodo analizado ha sido un periodo de considerable estabilidad, crecimiento económico y tasas de desempleo relativamente bajas.

Por último, cabe señalar que si bien los p-valores de los contrastes de HosmerLemeshow, mayores que 0,05 para todos los modelos, permiten aceptar la hipótesis nula que los modelos son adecuados y que si bien la introducción de estas nuevas variables aumenta la capacidad explicativa de los modelos, si los valores de la $\mathrm{R}^{2}$ de Nagelkerke se mantienen relativamente bajos, sólo puede indicar que existen otros factores determinantes que no han sido introducidos en los mismos como, por ejemplo, la intensidad competitiva del sector, la estrategia adoptada por los emprendedores o la posesión de activos intangibles como el capital relacional.

En la Tabla 5 se presenta un resumen de los resultados por lo que respecta a la validación de las hipótesis, como se puede observar, todas las hipótesis se cumplen para las empresas de negocios, excepto la H2B. Por el contrario, en el caso de las empresas sociales ninguna hipótesis se puede validar, excepto la H1, ya que la supervivencia de las empresas sociales y de negocios no presenta diferencias significativas.

Tabla 5. Resumen resultados validación hipótesis

\begin{tabular}{lcc}
\hline & Empresas de negocios & Empresas sociales \\
\hline $\begin{array}{l}\text { Hipótesis 1: Las empresas sociales y las de negocios presentan ra- } \\
\text { tios similares de supervivencia }\end{array}$ & Validada \\
$\begin{array}{l}\text { Hipótesis 2A: Existe relación positiva entre la formación del em- } \\
\text { prendedor y las tasas de supervivencia }\end{array}$ & Se cumple & No se cumple \\
$\begin{array}{l}\text { Hipótesis 2B: La relación entre formación del emprendedor y } \\
\text { supervivencia es mayor si la formación está relacionada con el } \\
\text { negocios }\end{array}$ & No se cumple & No se cumple \\
$\begin{array}{l}\text { Hipótesis 3: Existe una relación positiva entre la experiencia del } \\
\text { emprendedor y la supervivencia de las empresas }\end{array}$ & Se cumple & No se cumple \\
$\begin{array}{l}\text { Hipótesis 4: La supervivencia de las empresas es mayor si la mo- } \\
\text { tivación para emprender es la oportunidad que si es la necesidad }\end{array}$ & Se cumple & No se cumple \\
\hline
\end{tabular}




\section{Conclusiones}

Resulta innegable que el emprendimiento social constituye un fenómeno de creciente relevancia tanto en el ámbito económico como en el académico. Si bien presenta diferencias con el emprendimiento de negocios, fundamentalmente en cuanto a su misión, al tipo de oportunidades que permiten iniciar la actividad, al grado de dificultad para movilizar recursos y a la forma de medir sus resultados, no es menos cierto que ambos constituyen actividades innovadoras que identifican las oportunidades de modo similar y enfrentan retos también similares. Asimismo, las características de ambos tipos de emprendedores que suelen asociarse al éxito, parecen ser muy similares.

A pesar del creciente interés de la academia por el emprendimiento social, todavía constituye lo que Nicholls (2010) denomina un campo de estudio pre-paradigmático. Entre otras cuestiones, resulta necesario profundizar en el análisis comparativo del emprendimiento social y de negocios, e investigar si factores de éxito o fracaso de ambos tipos de emprendimiento son los mismos. Por ello, el presente trabajo analizó las diferencias en el nivel de supervivencia de ambos tipos de emprendimiento, así como la medida en que la formación y experiencia del emprendedor y su motivación para emprender afectan a sus probabilidades de supervivencia.

Los resultados obtenidos indican, en primer lugar, que la supervivencia de las empresas no parece depender de su naturaleza, es decir, de negocios o social, pues las diferencias en la probabilidad de sobrevivir entre ambos tipos de empresas no son significativas. Es este un dato especialmente relevante, máxime teniendo en cuenta la importante función social que pueden desempeñar las empresas sociales.

En segundo lugar, los resultados de los modelos logit que relacionan la formación y la experiencia del empresario con la supervivencia de la empresa revelan que, en el caso del emprendimiento de negocios, la formación y la experiencia reducen la probabilidad de cierre. No obstante, el papel del nivel de formación y el carácter afín o no de esta formación requieren un análisis más profundo pues, como se indicó al analizar los resultados, no se puede establecer cuál de las dos variables de formación tiene una mayor influencia sobre la supervivencia, puesto que los resultados en $t+3$ y $t+6$ divergen en el caso de las empresas de negocios. Dado que el porcentaje de emprendedores con un nivel de formación ESO+FPI que tienen formación afín no es significativamente superior al de los niveles superiores de formación, e incluye un porcentaje sólo sensiblemente más alto de emprendedores por necesidad, una posible explicación al hecho que su relación con la probabilidad de sobrevivir sea mayor que la que deriva de niveles de formación superiores, puede deberse a menores opciones de trabajo fuera de su propio negocio debido a su escaso nivel de preparación. En el caso del emprendimiento social, ni la formación, ni la experiencia del empresario están significativamente relacionadas con la supervivencia de la empresa.

En tercer lugar, cabe destacar que, en general, la motivación para emprender sí parece tener una influencia significativa en la probabilidad de sobrevivir, al menos en el caso de las empresas de negocios. En este caso, el riesgo de cerrar es entre 1,5 y 1,8 veces superior entre los empresarios por necesidad que entre los empresarios por oportunidad. Por el contrario, en el caso de las empresas sociales, no parecen existir diferencias en la supervivencia según motivación del empresario. Igualmente, las limitaciones de la muestra puedan dificultar la detección de relaciones débiles pero significativas entre motivación para emprender y supervivencia 
en este tipo de empresas lo que cabe señalar que la propia distinción entre emprendedor por necesidad u oportunidad puede quedar, en cierto modo, matizada por la propia naturaleza del emprendimiento social. En este caso, el objetivo prioritario es crear valor social, por encima de la satisfacción de las propias necesidades, por lo que puede perder importancia la situación laboral previa de este tipo de emprendedor. En cierto modo, crear una empresa social para cubrir las necesidades propias de empleo podría parecer un contrasentido aunque no se pueda excluir de partida esta posibilidad.

$\mathrm{Al}$ incluir en los modelos multivariantes, además de la formación, experiencia y motivación del empresario, el año de inicio de la actividad, el sector, el capital y el número de empleados estables, incluidos los propios emprendedores, se constata que el capital y la plantilla son factores relevantes en la supervivencia de cualquier tipo de empresa, $y$ en cualquier momento, en el sentido de que cuánto mayores son éstos, menor es el riesgo de cerrar. Más concretamente, en el caso del emprendimiento de negocios a los tres años, en general, tener estudios universitarios, experiencia afín y capital y plantilla grandes, reducen la probabilidad de cerrar la empresa. A los seis años, en general, tener formación afín, pertenecer al sector manufacturero, poseer capital y plantilla grandes, reducen la probabilidad de cierre. En el caso del emprendimiento social, tanto a los tres años como a los seis años, en general, tener un buen capital subvencionable y una gran plantilla reduce la probabilidad de cierre.

Del análisis de los resultados derivados del cálculo de las probabilidades de no sobrevivir se extrae una conclusión interesante, la formación, experiencia y motivación del empresario, el sector, el capital subvencionable y la plantilla de la empresa, no son factores definitivos para el cierre de una empresa a los tres años. Sin embargo, pasados tres años más, estos factores, aunque insuficientes para explicar las causas del cierre, ganan capacidad explicativa; es decir, en general, la formación, experiencia y motivación del empresario junto con el sector y el tamaño de la empresa son factores que juegan a favor de la supervivencia de la empresa con el paso de los años.

$\mathrm{Si}$ bien las limitaciones derivadas del tamaño de la muestra de empresas sociales, del sesgo que introduce el que los emprendedores analizados sean menores de treinta años o menores acompañados de socios mayores de esa edad, y el que la mayoría de las empresas sociales no sean puramente sociales, obligan a adoptar ciertas cautelas; se puede concluir que los resultados obtenidos señalan posibles diferencias en los factores que reducen significativamente la probabilidad de cierre de las empresas de negocios y las sociales. Las mayores dificultades que encuentran estas últimas, a la hora de movilizar recursos financieros y humanos, parecen constituir los únicos factores realmente determinantes a la hora de aumentar sus probabilidades de supervivencia. No obstante, se considera necesario replicar este tipo de estudios en otros ámbitos geográficos, eliminando el sesgo de la edad del emprendedor, aumentando la dispersión en el tamaño de las empresas consideradas y ampliando sensiblemente la muestra de empresas sociales. Asimismo, en la medida en que el tamaño de la muestra lo permita, sería conveniente considerar un mayor detalle en la identificación del sector de actividad o incluso considerar el grado de munificencia, dinamismo, complejidad e intensidad tecnológica de la industria en la que cada empresa compite. Por último, dada la baja capacidad explicativa de los modelos analizados, convendría analizar el efecto de otras variables explicativas como la estrategia de la empresa, la posesión de determinados activos intangibles, etc. 


\section{Referencias bibliográficas}

Agarwal, R. \& Audretsch. D. B. (2001). Does entry size matter? The impact of the life cycle and technology of firm survival. The Journal of Industrial Economics, 49(1), 21-43.

Agarwal, R., Echambadi, R., Franco, A. \& Sarkar, M. (2004). Knowledge transfer through inheritance: Spin-out generation, development, and performance. Academy of Management Journal, 47(4) 501-522.

Alvord, S. Brown, D. \& Letts, C. (2002). Social entrepreneurship and social transformation: an exploratory study. Hauser Center for Nonprofit Organizations, 15, 1-26.

Arthur, S., Keenoy, T., Scott-Cato, M. \& Smith, R. (2006). Where is the social in social enterprise? En D. Fuller, A.E.G. Jonas \& R. Lee (Eds.), Alternative spaces of economy, society and politics: interrogating alterity (pp. 207-222). Aldershot, UK: Ashgate.

Austin, J., Stevenson, H. \& Wei-Skillern, J. (2006). Social and Commercial Entrepreneurship: Same, Different, or Both? Entrepreneurship Theory and Practice, 3o(1), 1-22.

Barney, J.B. (1997). Gaining and sustaining competitive advantages. New York, NY: Addison-Wesley.

Bolton, W. \& Thompson, J. (2000). Entrepreneurs: Talent, Temperament, Technique. Oxford, uk: Butterworth Heinemann.

Bornstein, D. \& Davis, S. (2010). Social Entrepreneurship. What everyone needs to know. Oxford, UK: Oxford University Press.

Boschee, J. (1995). Some nonprofits are not only thinking about the unthinkable, they're doing it-running a profit. Across the Board, the Conference Board Magazine, $32(3), 20-25$.
Bosma, N. \& Levie, J. (2009). 2009 Global Report del Global Entrepreneurship Monitor. Recuperado el 15 de junio de 2011, de http://www.gemconsortium.org/docs/ download $/ 265$

Bosma, N., Van Praag, M. \& de Wit, G. (2000). Determinants of Successful Entrepreneurship. Research Report 0002/E, Scientific Analysis of Entrepreneurship and SMEs. Netherlands: EIM Business \& Policy Research.

Brock, D.D. (2008). Social Entrepreneurship Teaching Resources Handbook. Disponible en http://dx.doi.org/10.2139/ ssrn.1344412

Brüderl, J. \& Schussler, R. (1990). Organizational mortality: the liabilities of newness and adolescence. Administrative Science Quarterly, 35(3), 530-547.

Brüderl, J., Preisendörfer, P. \& Ziegler, R. (1992). Survival chances of newly founded business organizations. American Sociological Review, 57(2), 227-242.

Caneda, A. \& García, O. (2008, septiembre). Factores clave para el "éxito infantil" de las nuevas empresas. Documento no publicado presentado como ponencia en XVIII Congreso Nacional de ACEDE, León, España.

Castrogiovanni, G.J. (1996). Pre-startup planning and the survival of new small businesses: Theoretical linkages. Journal of Management, 22(6), 801-822.

Catford, J. (1998). Social entrepreneurs are vital for health promotion - but they need supportive environments too. Health Promotion international, 13(2), 95-97.

Churchill, N.C. \& Lewis, V.L. (1983). The five stages of small business growth. Harvard business review, 61(3), 30-50.

Cooper, A.C., Gimeno-Gaston, F.J. \& Woo, C.Y. (1994). Initial human and financial capital as predictors of new venture per- 
formance. Journal of Business Venturing, 9(5), 371-395.

Dees, J. (1998). The meaning of "social entrepreneurship". Recuperado el 10 de junio de 2011, de http://www.caseatduke.org/

Dencker, J.C., Gruber, M. \& Shah, S.K. (2009). Pre-entry knowledge, learning, and the survival of new firms. Organization Science, 20(3), 516-537.

Diario Oficial de la Comunidad Valenciana-Docv. (2007). Orden de 19 de diciembre, por la que se convoca concurso público para la concesión de ayudas para el equipamiento de empresas creadas por jóvenes. Recuperado el 10 de junio de 2011, de http://www.docv.gva.es/ datos/2007/01/23/pdf/2006_15363.pdf

Dorado, S. (2006). Social Entrepreneurial Ventures: Different Values so Different Process, no? Journal of Development Entrepreneurship, 11(4), 319-343.

Doyle, P. \& Ho, M. (2010). How opportunities develop in Social Entrepreneurship. Entrepreneurship Theory \& Practice, 34(4), 635-659.

Drayton, W. (2002). The Citizen Sector: Becoming as Entrepreneurial and Competitive as Business. California Management Review, 44(3), 120-133.

Dunne, P. \& Hughes, A. (1994). Age, size, growth and survival: UK companies in the 1980 . The Journal of Industrial Economics, 42(2), 115-140.

Evans, D.S. \& Leighton, L.S. (1989). Some empirical aspects of entrepreneurship. The American Economic Review, 79(3), 519-535.

Fogel, K., Lee, K. \& McCumber, W. (2011). Handbook of Research on Innovation \& Entrepreneurship (pp. 119-133). Northampton, MA: Edward Elgar.

Fritsch, M., Brixy, U. \& Falck, O. (2006). The effect of industry, region and time on new business survival - A multidimensional analysis. Review of Industrial Organization, 28(3), 285-306.

Gimeno, J., Folta, T., Cooper, A. \& Woo, C. (1997). Survival of the fittest? Entrepreneurial human capital and the persistence of underperforming firms. Administrative Science Quarterly, 42(4), 750-783.

Guzmán, A. \& Trujillo, M.A. (2008). Emprendimiento Social - Revisión de literatura. Estudios Gerenciales, 24(109), 105-125. Disponible en http://www.icesi. edu.co/revistas/index.php/estudios_ gerenciales/article/view/321/1139

Haber, S. \& Reichel, A. (2005). Identifying performance measures of small ventures - the case of the tourism industry. Journal of Small Business Management, 43(3), 257-286.

Harding, R. (2004). Social Enterprise: The New Economic Engine. Business Strategy Review, 15(4), 39-43.

Harris, J., Sapienza, H. \& Bowie, N. (2009). Ethics and entrepreneurship. Journal of Business Venturing, 24(5), 407-418.

Haugh, H. (2007). Community-Led Social Venture Creation. Entrepreneurship theory and practice, 31(2), 161-182.

Hayward, M.L.A., Shepherd, D.A. \& Griffin, D. (2006). A Hubris Theory of Entrepreneurship. Management Science, 52(2), 160-172.

Headd, B. (2003). Redefining Business Success: Distinguishing Between Closure and Failure. Small Business Economics, 21(1), 51-61.

Ho, Y. \& Wong, P. (2007). Financing, regulatory costs and entrepreneurial propensity. Small Business Economics, 28(2-3), 187-204.

Honig, B. (1998). What determines success? Examining the human, financial, and social capital of Jamaican microentrepreneurs. Journal of Business Venturing, 13(5), 371-394. 
Klepper, S. (2002). The capabilities of new firms and the evolution of the us automobile industry. Industrial Corporate Change, 11(4), 645-666.

Klepper, S. \& Simons, K. (2000). Dominance by birthright: Entry of prior radio producers and competitive ramifications in the U.S. television receiver industry. Strategic Management Journal, 21(1), 997-1016.

Knaup, A.E. (2005). Survival and Longevity in the business employment dynamics database. Monthly Labor Review, 128(5), 50-56.

Kolstad, I. (2007). Why Firms Should Not Always Maximize Profits. Journal of Business Ethics, 76(2), 137-145.

Korunka, C., Kessler, A., Frank, H. \& Lueger, M. (2010). Personal characteristics, resources, and environment as predictors of business survival. Journal of Occupational and Organizational Psychology, 83(4), 1025-1051.

Leadbeater, C. (1997). The Rise of the Social Entrepreneur. Londres: Demos.

Letowski, A. (2004). Le devenir des entrepreneurs créateurs ayant cessé lexploitation de leur entreprise. París: DECAs (Direction des Entreprises Commerciales, Artisanales et des Services).

Ligane, A. \& Olsen, S. (2004). Guidelines for Social Return on Investment. California Management Review, 46(3), 116-135.

Light, C.L. (2006). Reshaping social entrepreneurship. Stanford Social Innovation Review, 4(3), 45-51.

Lohman, R. (1989). A lettuce is non-animal: Towards a positive economics of voluntary action. Nonprofit \& Voluntary Sector Quarterly, 18(4), 367-383.

Lohman, R. (1992). The Commons: A multidisciplinary approach to nonprofit organization, voluntary action and philanthropy. Nonprofit \& Voluntary Sector Quarterly, 21(3), 309-323.
Mair, J. \& Martí, I. (2006). Social entrepreneurship research: A source of explanation, prediction, and delight. Journal of World Business, 41(1), 36-44.

Massetti, B.L. (2008). The Social Entrepreneurship Matrix as a "Tipping Point" for Economic Change. E:CO, 3(10), 1-8.

Mitchell, W. (1989). Whether and when? Probability and timing of incumbents' entry into emerging industrial subfields. Administrative Science Quarterly, 34(2), 208-230.

Mizic, N. \& Jacobson, R. (2003). Trading off between value creation and value appropriation: The financial implications of shifts in strategic emphasis. Journal of Marketing, 67(1), 63-76.

Mort, G.S., Weerawardena, J. \& Carnegie, K. (2003). Social entrepreneurship: Towards conceptualization. International Journal of Non-profit and Voluntary Sector Marketing, 8(1), 76-88.

Mount, J., Zinger, J.T. \& Forsyth, G. (1993). Organizing for Development in the Small Business. Long Range Planning, 26(5), 111-120.

Nicholls, A. (2010). The legitimacy of Social Entrepreneurship. Reflexive isomorphism in a pre-paradigmatic field. Entrepreneurship Theory \& Practice, 34(4), 611-633.

Peredo, A.M. \& McLean, M. (2006). Social Entrepreneurship: A Critical Review of the Concept. Journal of World Business, 41(1), 56-65.

Phillips, B.D. \& Kirchhoff, B.A. (1989). Formation, Growth and Survival: Small Firm Dynamics in the U.S. Economy. Small Business Economics, 1(1), 65-74.

Reis, T. (1999). Unleashing the new resources and entrepreneurship for the common good: A scan, synthesis and scenario for action. Recuperado el 20 de junio de 2011, de http://onlinelibrary.wiley.com/ doi/10.1002/pf.3206/abstract 
Reis, T. \& Clohesy, S. (2001). Unleashing new resources and entrepreneurship for the common good: A philanthropic renaissance. New Directions for Philanthropic Fundraising, 32, 109-144.

Reuber, A.R. \& Fischer, E. (1999). Understanding the consequences of founders' experience. Journal of Small Business Management, 37(2), 30-45.

Reynolds, P.D., Camp, S.M., Bygrave, W.D., Autio, E. \& Hay, M. (2001). Global Entrepreneurship Monitor 2001 Summary Report. Kansas City, KS: Kauffman Center for Entrepreneurial Leadership at the Ewing Marion Kauffman Foundation. Disponible en http://www.gemconsortium. org/docs/download/255

Ribeiro, D. \& Castrogiovanni, G. (2012). The impact of education, experience and inner circle advisors on SME performance: insights from a study of public development centers. Small Business Economics, 38(3), 333-349.

Roberts, D. \& Woods. C. (2005). Changing the world on a shoestring: The concept of social entrepreneurship. University of Auckland Business Review, 7(1), 45-51.

Santos, F. (2009). A positive theory of Social Entrepreneurship. INSEAD: The Business School for the world, 23, 1-54.

Sapienza, H.J. \& Grimm, C. (1997). Founder characteristics, start-up process, and strategy/structure variables as predictors of shoreline railroad performance. Entrepreneurship: Theory \& Practice, 22(1), 5-24.

Schiller, B.R. \& Crewson, P.E. (1997). Entrepreneurial Origins: A Longitudinal Inquiry. Economic Inquiry, 35(July), 523-531.

Schumpeter, J.A. (1942). Capitalism, socialism and democracy. New York, NY: Harper and Row.

Shane, S. \& Venkataraman, S. (2000). The promise of entrepreneurship as a field of research. Academy of Management Review, 25(1), 217-226.

Sheperd, D. (1999). Venture Capitalists' Assessment of New Venture Survival. Management Science, 45(5), 621-632.

Short, J.C., Moss, T.W. \& Lumpkin, G.T. (2009). Research in Social Entrepreneurship: Past Contributions and Future Opportunities. Strategic Entrepreneurship Journal, 3(2), 161-194.

Simms, M. (2009). Insights from a Management Prophet: Mary Parker Follett on Social Entrepreneurship. Business \& Society Review, 3(114), 249-363.

Social Enterprise Knowledge Network SEKN. (2006). Gestión efectiva de emprendimientos sociales: Lecciones extraídas de empresas y organizaciones de la sociedad civil en Iberoamérica. Washington, DC: Inter-American Development Bank.

Stinchcombe, A.L. (1965). Social Structure and Organizations. En J.G. March (Ed.), Handbook of Organizations (pp. 142-193). Chicago, IL: Rand McNally.

Sullivan, D.M. (2007). Stimulating Social Entrepreneurship: Can Support From Cities Make a Difference? Perspectives - Academy of Management, 21(1), 77-78.

Thompson, J.L. (2002). The world of the social entrepreneur. The International Journal of Public Sector Management, 15(5), 412-431.

Thompson, J.L., Alvy, G. \& Lees, A. (2000). Social entrepreneurship - a new look at the people and the potential. Management decision, 38(5), 328-338.

Van de Ven, A., Hudson, R. \& Schroeder, D. (1984). Designing new business startups. Entrepreneurial, organizational, and ecological considerations. Journal of Management, $10(1), 87-107$.

Van Praag, C.M. (2003). Business survival and success of young small business owners. Small Business Economics, 21(1), 1-17. 
Van Slyke, D.M. \& Newman, H.K. (2006). Venture Philanthropy and Social Entrepreneurship in Community Redevelopment. Case Study in Non Profit Management and Leadership, 16(3), 345-368.

Verheul, I. \& Thurik, R. (2000). Start-up capital: differences between male and female entrepreneurs, does gender matter? ERIM Report Series Research in Management ERS-2000-07-STR. Disponible en http:// ideas.repec.org/p/fth/miklrr/9910-e.html

Weitzman, M. \& Jalandoni, N. (2002). The New Nonprofit Almanac and Desk Reference. San Francisco, CA: Jossey Bass.

West, G. \& Noel, T. (2009). The impact of knowledge resources on new venture performance. Journal of Small Business Management, 47(1), 1-22.

Zadek, S. \& Thake, S. (1997) Send in the social entrepreneurs. New Statesman, 126(4339), 31-34.

Zahra, S.A., Gedajlovic, E., Neubaum, D.O. \& Shulman, J.M. (2009). A typology of social entrepreneurs: Motives, search processes and ethical challenges. Journal of Business Venturing, 24(5), 519-532. 